\title{
1. Why and how should the informal economy be revisited after 50 years? Jacques Charmes
}

Much has been written about the informal economy since the early times, when the concept was coined at the turn of the 1970s, and several revisiting exercises have been conducted since then, in particular by the OECD, in 1990 (Turnham, Salomé \& Schwarz, 1990) and in 2009 (Jütting \& de Laiglesia, 2009). So why would it be necessary to revisit once more an abundant literature? Several reasons make the case for such an exercise.

A first reason is that, despite the progress and the expansion of internationally agreed definitions, the confusion between the informal economy and the illegal economy is still widespread, and the concept of the informal economy is often used as a synonym for the shadow economy. It is therefore important to clarify the terms used in debates and to understand why the concept of the shadow economy as coined for describing the situation of developed economies eventually spread to the rest of the world. Furthermore, far from being confined to economic approaches, informality needs to be addressed, surveyed and understood from the points of view of other social sciences as well as of activists involved in the support of vulnerable populations who are dependent on the informal economy today.

A second reason to revisit is that it has been proposed that informality is the new normal, given the magnitude and trends of the informal economy within total employment and to a lesser extent in Gross Domestic Product (GDP). What does this say about economic development, contemporary capitalisms and contemporary societies, as well as about the social contracts that bind citizens to the states and the variety of their modes of government?

A third reason is that the boundaries of informality are shifting, not only because some previously illegal activities can become legal or tolerated - and, in any event, provide income (prostitution, for example) - , but also because the notion of work and employment is progressively changing, returning to the origins, when the provision of services for own consumption by households was considered as work. The initial concept of the informal economy, confined to production for the market, has been 


\section{Research handbook on development and the informal economy}

extended to production of goods for own final use (the so-called subsistence economy), and now - with the adoption of new concepts of work and employment by the 2013 International Conference of Labour Statisticians - the question has been raised as to whether it should be extended to production of services for own final use (the so-called care economy).

A fourth reason is that, with the adoption of Recommendation 204 on the transition from the informal to the formal economy by the International Labour Conference in 2015 (ILO, 2015), policies and strategies for promoting and supporting such a transition are on the agendas of governments. And in this regard, given the relation between the actors of the informal economy and the state, the role of associations and civil societies may prevail, so that a better knowledge of the actors and operators within the informal economy needs to emerge - and has emerged - at grassroots levels, originating from these actors of the social and solidarity economy for their own use and not only for use by official policy makers for public regulation.

This Research Handbook comprises four parts. Part I addresses the concepts and definitions, the methods of measurement and estimation, and the magnitude and characteristics of the informal economy phenomenon and of its components, as well as the global conception of strategies in relation to the concept and its various meanings. Special emphasis is placed on the changing scope and understanding of the phenomenon over time and across regions, and especially the related confusion with the shadow economy and the resulting misconceptions and misunderstandings. These changes are also examined in the light of development theories and thinking.

Part II discusses the margins or frontiers of the concept and explains to what extent some specific phenomena can be considered as components of the informal economy, both in their scope (unpaid care work, prostitution) and in their approach (cross-border trade and ethnic or religious networks).

Part III, entitled 'Giving Visibility and Voice to the Most Vulnerable: Observing, Participating, Supporting and Organising', deals with the dialectics of observation and action concerning three vulnerable groups of workers in the informal economy, from the most visible because of working in the open sun yet also the least known - the street vendors - to the equally visible but the least regarded - the waste pickers - and finally to the most invisible and equally ignored - the home-based workers.

Part IV, on skills, innovation and technological change in the informal economy, addresses issues such as the recognition of skills acquired in the informal sector, the role of apprenticeship and innovation as a 
potential step towards bottom-up industrialisation or as a means for self-reliance in refugee economies. It also attempts to assess the impact of technological change on the alleviation of women's burden of unpaid domestic and care work, or as a means for widening the benefits or loosening the clamps of the poor informal workers at the bottom of global supply chains, or also concerning the transformation of homebased piece workers into even more fragmented task- or click workers throughout the digitisation process.

\subsection{PART I: THE INFORMAL ECONOMY: CONCEPTS AND DEFINITIONS, METHODS OF MEASUREMENT AND ESTIMATION, MAGNITUDE AND CHARACTERISTICS, AND GLOBAL CONCEPTION OF STRATEGIES}

Part I comprises four chapters. The first two chapters deal with definitions, methods and estimates with regard not only to the informal economy, but also to the non-observed economy and the shadow economy, trying to disentangle the subtleties of these concepts, often mistakenly presented as synonymous. The two further chapters strive to position the approach of the informal economy across the spectrum of development theories and strategies since the early 1960s, to show how it has shaped current national policies in Kenya on the one hand, and current and still-in-process thinking about the informal economy in an international institution such as the International Labour Organization (ILO) on the other hand.

In Chapter 2, Jacques Charmes, the editor of this Handbook, recalls the origin of the concept of informality defined in relation to the state; reaching a unique and uniform definition was not achieved at speed, due to the variety of forms of government. This is why flexibility was an inherent characteristic of the concept, allowing for variations across countries and over time, without inhibiting data collection and international comparisons. Data are today available for more than a hundred developing and transition countries and for various periods since the 1970s, and an increasing number of works and studies attempt to identify and assess the determinants of informality. Still, many loopholes remain that are as many domains for future research, two of them being particularly emphasised: pluri-activity and patterns of growth (especially the absence of an intermediate sector, the so-called 'missing middle'). 


\section{Research handbook on development and the informal economy}

The debate - still ongoing - about illegal and legitimate activities in the informal economy explains the dichotomy of the concepts used in developing countries and in developed countries, the transition countries remaining in between as a space where both conceptions are in use.

In Chapter 3, Philippe Adair discusses the concepts of the "nonobserved' economy (NOE) and the 'shadow' economy (SE), which may have obscured the understanding of the informal economy in that this term has often been used as synonymous for the 'shadow' economy, all the more so as macro-modelling has made it possible to provide estimates of the shadow economy for almost all countries in the world. A wide spectrum of estimation methods (direct, such as tax audits, family expenditures or labour force surveys, as well as indirect such as the cash/deposit and currency demand ratio, labour inputs, electricity consumption and the structural modelling method) and estimates derived from the latter method are reviewed, and the derived estimates are compared with the measures of the NOE by national accounts for the European Union countries, based on the tabular approach recommended by Eurostat.

Chapter 4 is, for authors Dorothy McCormick, Paul Kamau and a team from the Institute for Development Studies in Nairobi (an institute that played a major role in the first-ever coined definition of the informal sector at the beginning of the 1970s), an opportunity to review development and growth theories and strategies applied, in the context of the newly independent economies, by scholars and policy makers: from the modernisation and dependency theories, the basic needs, sustainable livelihoods and human development approaches, to the current neoliberal strategies. The chapter explores how the linkages between informality and national development have evolved over time through the national policy lenses, the manifestation of informality and its contribution to national development. Grasping with the practical issues of the regulation and the enhancement of a burgeoning and spontaneous sector, policy makers attempted to design appropriate policies. It is important to see what place and role were given to informality in development studies' thinking and policy designs, and what impacts the emergence of the concept has had. Kenya, the country where the concept of the informal sector was born, has developed, since the origin, successive policy papers dedicated to this sector without - significantly and strangely - naming it as such, preferring to refer to Micro, Small and Medium Enterprises (MSMEs), a widely shared behaviour among policy makers in Africa and elsewhere. The result is that government actions, coming from different perspectives, make coherent policy difficult to achieve. 
Similarly, but in a broader perspective, Frédéric Lapeyre, who is coordinating the transition to formality at the ILO, reviews, in Chapter 5, the various and successive ways of thinking and proposed strategies, designed and supported by the ILO, which is the main international actor in the field. In this respect, the chapter complements Chapter 4 in that it gives room for broader generalisation. From this perspective, the chapter attempts to show that public policies aiming at facilitating transitions towards the formal economy should be a means to establish inclusive development and not an end in itself with the intention of increasing fiscal space or better controlling the informal economy. It targets the adaptive capacities of informal economy actors, describing how these actors systematically reposition themselves vis-à-vis the state, markets, and international and national policies to secure their livelihoods, and explains how this triggers a need to reformulate questions relating to policy intervention based on a more thorough understanding of the perspective of the informal economy actors.

Recalling the origins and the evolution of thinking about informality, and the transition to formality through the various programmes of the ILO and the variety of mainstream development theories, until and since the adoption of Recommendation 204 on the transition from the informal to the formal economy by the International Labour Conference in 2015, the chapter suggests that these changes have led to a democratic 'new deal', in short the rewriting of the social contract between the people and the state. This includes consolidating local associative movements (see chapters 10,11 and 12) and creating an inclusive state that guarantees collective freedoms, social justice and the construction of territories where 'sustainable good life' is possible. The chapter concludes by reflecting on the importance of a better understanding of everyday grassroots practices and initiatives of actors in the informal economy to give rise to a 'reinvention of being and doing together' and on the impossibility of a universal framework for intervention. Diverse responses are possible; these are currently work in progress or likely to emerge.

\subsection{PART II: RECONSIDERING THE MARGINS AND FRONTIERS OF THE INFORMAL ECONOMY}

Part II is made up of three chapters. The first discusses the ongoing and probably ineluctable enlargement process of what is considered as the economic activity as applied to the invisible unpaid care work mainly performed by women and not even considered as informal, that is, 
worthy of consideration in the measurement of economic performances. Each of the two other chapters addresses a phenomenon that is indeed at the opposite end of the spectrum within the scope of this Handbook: on the one hand, the so-called 'oldest profession in the world', prostitution, which lies in between legality and illegality, and, on the other hand, activities that mirror multinational corporate firms in the informal economy yet the mirror makes them invisible - that is, the ethnic or religious networks of trade entrepreneurs in Western and Central Africa.

In Chapter 6, Nancy Folbre notes that far more attention has been paid to upward linkages between the informal economy and the formal economy than to downward linkages with the unpaid care economy of non-market family services, and she stresses the impact that such a change in perspective could have in terms of the size and dynamics of informal employment as a whole. She explores the changes - between innovation and resistance - that have intervened in representations and categorisations of work and employment (especially housekeepers and family workers) over the nineteenth and twentieth centuries, across various schools of thought and among authors, as an introduction to the more contemporaneous and currently ongoing discussions and interactions between the System of National Accounts (SNA) and the international concepts of work and employment, two frameworks that have so huge an impact on our interpretations and understanding of the economy.

The fuzziness of the distinction made by national accountants and labour statisticians between productive/non-productive, economic/noneconomic, market/non-market or SNA/non-SNA activities is emphasised and scrutinised through the constant retroaction between the concepts of national accounting on the one hand and the concepts of labour force, work and employment on the other hand. Encouraging readers to rethink these binaries, which result in concealing an immense part of women's contribution to the economy and to general well-being, and in order to better understand the challenges at stake, Nancy Folbre takes an illustrative example: milking a cow is - theoretically - taken into account in the GDP as a good produced for own final consumption, whereas breastfeeding - an unpaid care service - is not.

As a matter of fact, whereas the SNA has early introduced the production of goods for own final consumption by households within the boundaries of GDP measurement, and has constantly kept the provision of services for own final consumption outside these boundaries, the recent evolution in the concepts of work and employment coined by labour statisticians may have opened the door to a broader conception 
including unpaid care work as a form of work, but restricting employment to work for pay or profit. Will the SNA follow with the enlargement of its framework to include unpaid care work, or with the shrinkage of that framework to employment for pay or profit? The story is not yet told.

Chapter 7, by Philippe Adair and Oksana Nezhyvenko, examines the case of prostitution, which is, paradoxically, not recognised as a profession in the framework of labour force concepts, but is recommended to be taken into account in the compilation of GDP by Eurostat. It is therefore interesting to focus on an activity that is on the edge of both concepts of informality and illegality, provided that it can be legal or illegal and difficult to disentangle from sexual exploitation and human trafficking, depending on national legislations, and most often undeclared. Moreover, as recalled by the authors, contemporaneous legislations and policies originate in the works of three classical economists, Mandeville, Malthus and Stuart Mill, which inspired the various regimes that can be observed today across countries and allow for studying the phenomenon on crosssectional data: prohibition, regulation and abolition. The chapter is a good example of how to tackle such an invisible and coerced as well as non-coerced activity, by using multiple approaches and sources (on the demand side, and on the supply side) for 39 European countries and disentangling them. These sources are tested through econometric techniques and checked against national accounts estimates. Among the findings, epidemiological data on HIV prevalence are revealed to be the most reliable, and the magnitude of female sex workers, which is highly dependent on the prostitution regime, shows an asymmetry between richer non-transition countries and poorer transition countries.

In a completely different context and with a different scientific apparatus, at the opposite of the spectrum, in Chapter 8, Stephen Golub and Mirayda Martinez convene the historical approach to throw light on the powerful networks innervating an activity that is also on the edge of the concepts of informality and illegality, that is, cross-border trade that flirts with, or tests the limits of, smuggling and corruption. Noting that the informal sector may be highly organised whereas the official institutions are dysfunctional with a high prevalence of corruption and a lack of protection of property rights, the authors stress that, in such contexts, kinship groups provide their members with social capital that serves to enforce binding agreements, minimising trade transaction costs, optimising market information, and facilitating credit and business creation as well as an informal social protection system. 
Focusing on the Mourides of Senegal, the Yoruba of Nigeria, Benin and Togo, the Haoussa of Northern Nigeria and the Igbos of Southeastern Nigeria, the chapter traces the constitution of these kinships' networks back to the precolonial and colonial periods, to explain what they have become and the strength they have acquired. Over time, these networks achieved settling in trade towns across regions and countries, transcending national borders, venturing up to Europe, North America and even China, opening and strengthening major trade routes through a large diaspora able to supply brokers, temporary lodging, access to local markets, and various facilities and services at different points on these routes. It is, however, doubtful, according to the authors, that these successes led to industrial development and integration in the global economy as it occurred in East Asia.

It is easy to see that the usual analytical tools of economists fail to capture the complexity of such networks, of such global value chains, most often limited to trade, and whose opacity makes it difficult to find out the overall turnover, value added, profit and number of jobs mobilised, from the smallest street vendors to the highest-earning CEOs.

\subsection{PART III: GIVING VISIBILITY AND VOICE TO THE MOST VULNERABLE: OBSERVING, PARTICIPATING, SUPPORTING AND ORGANISING}

This part consists of four chapters that showcase the profiles of three professions. All the professions' omnipresence and their role reveal them as major actors in the functioning of cities in developing countries: two are extremely visible - street vendors and waste pickers - and one is invisible - the home-based workers. While the first chapter is based on ground-level observation of street vendors in Tunisia by an anthropologist, the three subsequent chapters express and attempt to design the type of responses needed for supporting the smooth transition of the most vulnerable to the formal economy or at least towards an improvement of their working and living conditions. These responses are far from the macro-policies and global measures usually implemented by the state; far from the incentives or the coercive measures designed by government actors. The chapters illustrate the principles and findings of the action research approaches privileged by WIEGO (Women in Informal Employment: Globalizing and Organizing), the international network of researchers and activists dedicated to the support of women informal workers across the world, and especially focus on the three vulnerable groups of 
informal workers using a gender lens, as women are even more vulnerable among these groups of workers. As a matter of fact, policies addressing informality require bottom-up approaches, rather than macro top-down strategies. In this sense, this part of the Handbook highlights the other side of, and is complementary to, the global strategies that are emphasised in parts I and II.

In Chapter 9, Laurence Michalak privileges an anthropological approach of five very concrete types of street vendor in Tunis, namely a pine tar vendor, a breadstick vendor, a vendor of Libyan goods, a beggar woman and a contraband cigarettes vendor. The approach is entirely qualitative and based on quasi-daily or frequent (daily or weekly) encounters with the persons over a long enough period of time and through short questionings or talks. The result leads the reader to emerge in the concreteness of a universe that perhaps was only grasped up to this point through generalisations or rather abstract theorisations. Of course, the representativeness of these observations is not ensured, but that is not the point insofar as this kind of knowledge is shown to be essential for better understanding of the everyday life of the tiny mob that constitutes the fringes of the invisible workforce, engaged in petty activities to earn a living. The chapter also provides the opportunity to discuss some common assertions or debates about the informal economy, such as competition and cooperation between actors, unfair competition and the non-payment of taxes, subsistence and multiple jobs holding, legality and illegality. Policy measures and government attitudes are also discussed. Furthermore, the chapter provides the opportunity to discuss the pros and cons of the variety of methodologies that are required for capturing the reality of informal activities and the variety of studies and surveys conducted in Tunisia with this aim in mind.

In Chapter 10, Sonia Maria Dias and Lucía Fernández, drawing on three experiences of waste pickers' cooperatives in Pune (India), Bogota (Colombia) and Belo Horizonte (Brazil), highlight processes of formalisation from the ground. They review the literature on cooperation models with special emphasis on co-production and participatory governance, in which Membership-Based Organisations (MBOs) are rooted. At the crossroads of the debates on social capital, governance and formal/ informal linkages, these reflections lead the authors to envision a complete re-conceptualisation of service provision (in this case, waste collection and recycling) as a process of social construction in which rules, norms and institutional frameworks are negotiated by or with MBOs, rather than taken as given by the authorities. Drawing on ILO/WIEGO research on cooperatives, WIEGO's rights-based approach to securing livelihoods and decent jobs is then presented, which intends 
to shape alternative routes to formalisation. Organising is a key pillar of the approach and cooperatives are an adequate means for that, allowing acknowledgement of the key role of waste pickers in urban metabolism as service providers, beneficiaries of integration to public schemes or procurement contracts, and finally full integration in the global value chain of recycling, leading to the socio-economic inclusion of the informal workers.

In Belo Horizonte, the cooperatives of waste pickers struggled for the acknowledgement of the rights to the city for their members and a strong integration ('embeddedness') was achieved between MBOs and local authorities that provided infrastructure for operations, such as recycling warehouses and equipment, as well as capacity building and educational campaigns, through which waste pickers improve their self-esteem and gain social visibility. These successes have survived changes in government, though continuous struggles remain necessary, and for the most recent period there have been impacts of cuts in national funding lines and closing of participatory democracy spaces.

The Bogota case is a tale of the continuous struggle of waste pickers' MBOs, whose livelihoods had been threatened by the privatisation of public waste collection, in which exclusive contracts were granted to private formal companies. The legal campaign launched by MBOs for their rights to collect and recycle waste culminated in the Constitutional Court ruling that the municipal government's tendering process had violated the basic rights of the waste-picking community. MBOs were consequently allowed to prepare, with the support of WIEGO, a bid for contract - and they eventually won the bid. But vested interests never ceased, and on the occasion of mayoral elections and public campaigns it was claimed that the arrangements were undermining free competition and were therefore illegal.

Lastly, Pune is another case where the municipality entered into contractual agreements with the community of waste pickers organised in cooperatives to ensure waste segregation, door-to-door collection and the processing of recyclable materials: informal workers are paid with users' fees, the municipality covers health insurance, and social inclusion is pursued through various accompanying strategies such as credit provision, education and group life insurance, among others.

In the three cases, a common feature emerges, which is the claim for the rights to the city, the rights to access the urban commons that are waste resources, carving the legal framework in an enabling environment for the activities of the working poor.

In Chapter 11, and further to Chapter 10, Françoise Carré, Pat Horn and Chris Bonner remind us that informal workers, especially the 
self-employed and among them street vendors and home-based workers, do not have the power to withhold labour and to strike, even if waste pickers and transport workers, for example, can disrupt city life. Their actions and associations can take their roots in the formal trade union tradition, or in broad social movements, or also in the cooperative and social and solidarity economy. Moreover, these workers are confronted with a multiplicity of actors: public (municipalities and other levels of government), collective associations (regulating local markets) and private suppliers of the goods they sell in the case of street vendors, or contractors in the case of home-based workers (outworkers). Thereupon collective negotiations have neither the same meaning nor the same forms as they have for formal employees. The chapter, drawing on first-hand and empirical materials originating in WIEGO's experiences and access to direct players in the field, attempts to set up a typology of negotiations (day to day, ad hoc, consultations, roundtables/policy dialogues, regular, statutory) in combination with: who or what triggers, how (advocacy or representation) and whether the negotiation is bilateral or multilateral. Disentangling the contradictions between national and local legislation, as well as constitutional rights and international commitments with ratified conventions, informal worker organisations gain legitimation in conducting negotiations in local and national settings including jurisdictional courts, and also in international fora, such as the international labour conferences, where they can make their voice and their case heard and so eventually transform norms and practices.

Some illustrative examples are provided for each identified type of negotiation, with their ups and downs: for street vendors in Liberia and Senegal, Lesotho and Kenya. In Peru, where the right to trade may be guaranteed by the constitution, but not respected at the local level, Lima's City Council passed an ordinance to govern how individuals are authorised to sell in public spaces, but this is vulnerable to government change and requires constant mobilisation. In India, where the 2014 Street Vendors Act guarantees statutory negotiations, its bypass by the municipality of Delhi led the town's vending committees to bring the municipality to court, which ended in the obligation for the municipality to reinstate the evicted vendors at their original vending sites. Other examples concern home-based workers, for instance the bidi (traditional cigarettes) rollers in Gujarat (India), whose associations, supported by the Self Employed Women's Association (SEWA), negotiated a minimum piece rate/wage with contractors as well as contributions to a welfare fund.

In Chapter 12, Ana Carolina Ogando and Jenna Harvey emphasise the principles and objectives of action research (AR) and participatory action 
research (PAR) guiding researchers involved in the co-production of knowledge aimed at improving directly the living and working conditions of the vulnerable workers in the informal economy. Besides eliciting external credibility from among their peers, action researchers have also to gain trust and credibility from those in charge of taking action and those for whom the action is intended. Social change is their objective and it must be defined, as well as the approach to achieve it, in connection with the target groups and with their participation, the ultimate objective being the ownership of the research results by the subjects themselves. Hence the co-production of knowledge that characterises WIEGO's approach and requires the building of individual but also collective capacities, and the systematic collection and construction of data for action in local and global advocacy processes. Grassroots groups and movements, and membership-based organisations, are strengthened, building alliances and solidarity in order to shape strategies and be enabled to engage in discussions and negotiations with the state. Various examples are provided and analysed, such as the Informal Economy Monitoring Study (IEMS) designed and conducted by the WIEGO network in ten cities of developing countries, along the above principles, which helped the associations of informal workers to push their demands with state actors, or to factually de-construct some myths about informality such as 'unfair competition' and non-payment of taxes by street vendors, in the case of Ghana for example, or to enable the cooperatives of recyclers of Bogota to claim for their rights and be allowed and able to bid for the market of waste collection and recycling.

\subsection{PART IV: SKILLS, INNOVATION AND IMPACT OF TECHNOLOGICAL CHANGE IN THE INFORMAL ECONOMY}

Part IV deals with two characteristics that seem antinomic of informality: skills and innovation. For most policy makers the informal economy is in need of more skills, but it is rarely envisaged as a source of provision of skills that would deserve to be strengthened, complemented, supported and recognised. Similarly, innovation is rarely sought after in this sector of the economy, whereas an identification and a better account of this potential reserve of innovations could be an opportunity to unleash such a potential. The first chapter focuses on skills and apprenticeship in the informal sector, the next two chapters examine the status of innovation in the informal economy in Africa and in refugee economies, and the final 
chapter attempts to measure or predict the impacts of technological change on the livelihoods of women in the informal economy.

Chapter 13 is dedicated to skills development and the informal sector, and appears to offer an encouragement to examine in more depth the range of approaches to, and connections between, these two major concepts. Kenneth King first relates the long history of interrelationships between skills training and the informal sector: informally acquired skills through traditional apprenticeship in particular, and non-formal education and training, had attracted the attention of researchers even before the concept of the informal sector appeared, and it was a long time before they were formally recognised. Skills training is a concept that encompasses the formal system of Technical and Vocational Education and Training (TVET) and includes non-formal modes of skills acquisition that may occur in various environments and even within the formal sector itself.

The chapter goes through and analyses the literature on these topics, especially the main world reports of international institutions that punctuated the last decade: the World Bank reports and one of its major programmes in the field, the UN 2030 agenda for sustainable development, and, above all, the UNESCO reports and recommendations. The most recent World Development reports by the World Bank that focus on education and jobs leave little room for non-formal education and training, unless negatively, and do not attribute any interest in them nor any return to work, contrary to an earlier report also published by the World Bank in 2013. In contrast, the UNESCO reports monitoring the international commitments on Education for All, place greater emphasis on the role of non-formal education and training. They focus on unleashing the potential of TVET, and in particular apprenticeship that can be strengthened through the improvement of skills among masters or mistresses operating in the various crafts of the informal sector, a pillar of formalisation strategies. Recognition of prior learning can also be a means of such a process, but it is not realistic to assume that it can lead by itself to formal-sector jobs.

The chapter concludes that more research would be needed concerning the relevance of primary, secondary and college education in the informal economies that prevail in so many countries. Furthermore, there is an urgent need to know more about the varieties of skill acquisition outside formal TVET, especially in traditional apprenticeships, but also in the informal ways of acquisition within the formal sector, and to understand to what extent these systems are changing and accommodating, in particular those associated with social media. 
This leads us to the next chapters, on innovation. In Chapter 14 Erika Kraemer-Mbula and Lorenza Monaco seek to rediscover the potential of the informal economy for triggering an industrialisation process that has been continuously and idly struggling for decades to reach uncertain achievements. To fulfil this aim, it is necessary to adopt an approach in terms of systems rather than individual firms and to think of industrialisation as a bottom-up process: the informal economy can be seen as an incubator and innovation as also being generated by grassroots economic activities and micro- and small enterprises that need to be supported. In other words, bottom-up industrialisation could be an alternative path to valorise local resources and capabilities. Such an approach thus requires rethinking informality as well as innovation.

Rethinking informality means acknowledging the multiplicity and complexity of its causes and determinants, and recognising it as a functional part of the formal economy itself and as an incubator of creative practices. Rethinking innovation means recognising that firms' ability to identify new ideas and transform them into new or improved products, services or processes also exists in informal enterprises, for example adaptation of machinery, or changes in product design and packaging, or problem solving too. It also means a broader understanding of the processes involved, in particular the underlying learning processes associated with innovation and the role of informal networking for building trust and cooperation. Whereas technological innovations require skills and capital, non-technological innovations (such as new organisational or marketing methods) also exist in the informal enterprises and they may be even more important and more inclusive than the former in that they better address the needs of communities excluded from formal markets.

After reviewing the limited but growing literature connecting entrepreneurship, informality and innovation, the chapter provides several examples of industrialisation from below, extracted from the archives of the Open African Innovation Research (OpenAIR) network, which collects the creative practices emerging 'out of necessity, vulnerability and scarcity'. Emphasised are the collaborative platforms where small entrepreneurs can share tools, knowledge, experiences and workspace, resulting in skills development through learning by doing, knowledge sharing and cooperation, as first steps towards scaling up.

These types of clustering are also emphasised in Chapter 15 by Jeremy de Beer and Nicole Tumaine; this chapter aims at highlighting the role of refugees within innovation ecosystems, especially in the informal sector. In this perspective, the authors bring together three disconnected fields of research - informal sector, innovation and refugee economies - in order 
to show that, far from being a drain, refugees are contributing to their hosts' economies. The refugee economies, often characterised by confinement and the legal inability to work, own property or access capital through banking systems, do not offer any other opportunity than to engage with informal activities. In these contexts, innovation is defined as the adaptation process through which refugees maximise opportunities and mitigate constraints in the face of extreme market distortions. The chapter draws on the activities of two networks: OpenAIR and the Refugee Economies research project. It emphasises the role of grassroots intermediary organisations that help innovators in refugee economies to overcome the obstacles typical of the informal economy and to reach a certain degree of self-reliance by nurturing entrepreneurial and innovative spirits. In this sense, innovation lies in the services provided by these intermediary institutions/associations and in their organisation itself: intermediaries serve as platforms to find community-based solutions to the problems of the community that remain unaddressed by humanitarian agencies in charge of the camps. However, some of these solutions can be technical, such as the fabrication of simple solar power chargers for mobile phones, for instance. The chapter showcases five examples of such intermediaries that belong to the social and solidarity economy: three in Uganda (a textbook case, as it is known for its more permissive policies towards refugees and the diversity of nationalities and activities in urban and camp settings), one in South Sudan and one in Canada (in relation to Syrian refugees).

Finally, in Chapter 16, Jacques Charmes analyses the impact of technological change on the situation of women in the informal economy. Across the world and over time, female labour force participation rates are lower than male rates, even as the gender gap seems downward oriented in the recent period. The burden of unpaid domestic and care work rests mainly on women's shoulders, and the socio-cultural or familial necessity to perform their productive work at home considerably restricts opportunities for employment. As a consequence, the risk of being bound to work informally, especially as home-based workers, is much higher for women than for men. The chapter recalls some statistical evidences on these matters.

Technological changes can have an impact on women's working and living conditions in various ways. In developing countries, mitigating the burden of domestic tasks remains limited, but opportunities for time saving exist in unpaid activities such as water and wood/fuel fetching through the introduction of various improved and adapted technologies. ICTs, and especially mobile phones, are also important means within reach of informal micro-businesses or even income-generating activities. 
The chapter provides illustrative examples of poor women shea nuts gatherers and shea butter processors in Northern Ghana who were able to widen their place at the bottom of the global value chain, and of informal workers benefiting from a platform of services in Mozambique. Lastly, digitisation, robotisation and the economy of platforms, far from being unrelated to the development of the informal economy, are revealed to be new sources of informalisation in various industries, including femaledominated industries, all the more so as working from home still remains essential for vulnerable working women such as single mothers. Click workers who are more likely to be home based thus replace the former task workers and the seeds of labour-informalisation processes remain perennial at the heart of the new industrial revolution.

\subsection{IN CONCLUSION}

This Research Handbook does not pretend to cover all topics and issues related to the informal economy. The scientific editor's choice has been to provide a wide and diversified range of approaches likely to make scholars and researchers aware of the issues to be tackled and the challenges at stake within this rather recent field of knowledge in economics and the social sciences at large. The Handbook offers historical, theoretical, political and practical entries into a still-burgeoning and debated field of research. It provides some indications or orientations towards domains that still require more in-depth investigations for a better understanding of a phenomenon concerning a majority of the labour force at world level, making it possible for the working poor to earn a living, providing a number of them - in particular women - with new opportunities. Such approaches pave the way for an improvement of the living and working conditions of informal workers and a renewed discussion about the social contract between the 'excluded' and the state. Among the suggested innovations, it proposes an inclusive approach broadening the scope of research to encompass unpaid domestic and care work in order to better understand and grasp the obstacles and disadvantages faced by women towards their empowerment.

\section{REFERENCES}

ILO (2015), Recommendation 204 - Recommendation on the Transition from the Informal to the Formal Economy, adopted by the ILC at its 104th session, Geneva, 12 June. 
Jütting, J.P. \& de Laiglesia, J.R. (eds) (2009), Is Informal Normal? Towards More and Better Jobs in Developing Countries, Paris: OECD.

Turnham, D., Salomé, B. \& Schwartz, A. (eds) (1990), The Informal Sector Revisited, Paris: OECD. 